\title{
Spatial genetic structure of the ectoparasite Ixodes uriae within breeding cliffs of its colonial seabird host
}

\author{
KD McCoy, ${ }^{1,3}$ C Tirard ${ }^{1}$ and Y Michalakis ${ }^{2}$ \\ ${ }^{1}$ Laboratoire de Parasitologie Evolutive, Université Paris VI - CNRS UMR 7103, 7 quai St Bernard, Paris F-75005, France; ${ }^{2}$ Centre \\ d'Etudes sur le Polymorphisme des Microorganismes, IRD - CNRS UMR 9926, IRD, 911 Avenue Agropolis, Montpellier F-34032, \\ France; ${ }^{3}$ Department of Biology, Queen's University, Kingston, Ontario, Canada K7L 3N6
}

To examine the potential importance of the spatial subdivision of hosts for the functioning of parasite populations, we analysed patterns of local genetic structure within natural populations of the seabird ectoparasite, Ixodes uriae, at the scale of the host breeding cliff. The seabird hosts of this parasite nest in dense colonies with a hierarchical spatial organisation (individual nests-breeding cliffs-colony). Using eight microsatellite markers and samples from three breeding cliffs of the Black-legged kittiwake (Rissa tridactyla), we found that tick populations were indeed genetically structured at this spatial scale. However, the nature of this structuring depended on the characteristics of the cliffs considered. Both the host nest and cliff topography seemed to be important factors in the isolation of tick groups, but their relative roles may depend on the size of the local parasite population. We found no evidence of isolation by distance within a cliff suggesting that independent tick dispersal may not be a significant force influencing population structure in highly infested cliffs. However, genetic structure seemed to decrease with tick life stage, nymphal ticks being more strongly structured than adult ticks. These results may be related to the clustering of tick progeny combined with differential mortality and dispersal probabilities of each life stage. Overall, results indicate that the spatial organisation of hosts can indeed have important consequences for the population genetic structure of their parasites and, thus, may modify parasite dynamics and the scale at which local coevolutionary processes occur.

Heredity (2003) 91, 422-429. doi:10.1038/sj.hdy.6800339

Keywords: dispersal; gene flow; microsatellite; tick; Rissa tridactyla; spatial autocorrelation

\section{Introduction}

Parasites live in a highly subdivided world and, as such, the spatial organisation of hosts is particularly important to take into account when considering the dynamics and evolution of host-parasite interactions. At the scale of the host patch, parasites are subdivided among host individuals and typically show an aggregated distribution, with a few hosts harbouring most parasites (Shaw and Dobson, 1995). This aggregation may be related to certain characteristics of the parasite itself or to the spatial distribution of susceptible hosts (Wassom et al, 1986; Poulin, 1998). Subdivision among hosts may result in reduced gene flow between parasite groups, and thus should be reflected in the pattern of genetic structuring of parasite individuals within the host population (Wright, 1943). This substructure may, in turn, influence the outcome of coevolutionary interactions, such as the evolution of local host/parasite adaptation, host resistance and parasite virulence (Antonovics et al, 1997). Several studies have examined genetic variation within-

Correspondence: KD McCoy, Department of Biology, Queen's University, Kingston, Ontario, Canada K7L 3N6. E-mail: mccoyk@biology.queensu.ca Received 26 April 2003 and between-host individuals and have found that parasites with complex life cycles and mobile hosts are often characterised by populations with high within-host genetic variation and low between-host differentiation (eg, Dame et al, 1993; Blouin et al, 1999; Jobet et al, 2000, but see Mulvey et al, 1991). However, none of these studies explicitly considers the spatial arrangement of host individuals within the population.

Here, we examine local parasite population structure in a spatially subdivided system involving the tick Ixodes uriae and one of its seabird hosts, the Black-legged kittiwake Rissa tridactyla. This tick is a common ectoparasite of colonial-nesting seabirds in the circumpolar areas of both hemispheres (Sonenshine, 1993) and its populations can be subdivided at several spatial scales relative to its host: among breeding colonies, among breeding patches within colonies and among nests within breeding patches (Boulinier et al, 1996; McCoy et al, 1999). I. uriae is considered to impact host reproductive success negatively (eg, Morbey, 1996) and to alter host habitat selection decisions (Danchin et al., 1998; Boulinier et al, 2001). In addition, it is the vector of several avian arboviruses and bacteria, including human disease-causing strains of Borrelia burgdorferi s.l. (Olsen et al, 1993). The local dynamics of this tick can thus play 
an important role in host population dynamics and in the outcome of the coevolutionary interactions between host, parasite and microparasite.

Using ticks collected in three kittiwake breeding patches, we tested specific predictions related to local parasite genetic structure. Different mechanisms leading to parasite aggregation may result in different patterns of spatial genetic structure. For each host patch, we examined tick genetic structure in relation to the distribution of hosts (ie, location of nests), the topography of the habitat in terms of parasite refuges and the local parasite density and prevalence.

\section{Biological model and specific predictions}

I. uriae commonly parasitises Black-legged kittiwakes in the northern hemisphere (eg, Eveleigh and Threlfall, 1974). This tick was considered to be a generalist parasite of seabirds, but recent genetic work has shown that hostassociated races, in particular for the kittiwake, do occur (McCoy et al, 2001). The life cycle of this parasite generally takes 4 years to complete and consists of three active stages: larva, nymph and adult (Eveleigh and Threlfall, 1974). In order to pass from one stage to the next, the tick must take a single blood meal on its host. The length of this meal depends on the stage considered, but typically lasts 3-9 days (Eveleigh and Threlfall, 1974) and involves an intimate interaction between the host immune response and the parasite's evasive mechanisms (Wikel, 1996). Males of I. uriae do not feed in the adult stage and females die immediately after laying a single batch of several hundred eggs. Aside from the short period on the host to feed, the tick lives in the habitat surrounding the host nesting area. Although the importance of habitat in the evolution of ticks has been debated (Klompen et al, 1996), suitable habitat availability should clearly play a key role in the local population dynamics of this species.

The Black-legged kittiwake is a long-lived seabird that nests on vertical cliffs in dense colonies, typically containing from a few hundred to several thousand breeding pairs. These large colonies are often subdivided into discrete breeding cliffs (ie, patches). The kittiwake is pelagic, spending most of its life at sea and only a few months a year in the colony to breed. During the reproductive period, the movements of breeding birds on land are largely restricted to the area of the nest site. A breeding pair can produce up to three chicks each season and typically shows high philopatry to the nest site between years. This species can also display relatively high natal philopatry depending on local conditions (Boulinier et al, 2001).

The local infestation dynamics of $I$. uriae in kittiwake colonies has been described at several spatial scales (Danchin, 1992; Boulinier et al, 1996; Boulinier and Danchin, 1996; Danchin et al, 1998; McCoy et al, 1999). Within a single breeding cliff, parasites are highly aggregated among nests, but not among chicks of the same nest (Boulinier et al, 1996), and nest infestation is spatially autocorrelated (Boulinier, 1995; McCoy et al, 1999). Tick infestation is also temporally autocorrelated between years at the cliff level (Danchin et al, 1998), as would be expected for a parasite that spends most of its life in the substrate of the host breeding site. Local infestation levels typically increase for the first 30 years after breeding colony establishment and level off thereafter (Danchin, 1992).

The aggregated nature of tick infestation within kittiwake breeding cliffs may be the outcome of several different factors. For example, patterns of spatial patchiness may largely be due to a combination of time, limited local dispersal and the availability of off-host shelters. Indeed, these parasites are considered to have a limited capacity for independent dispersal (Falco and Fish, 1991). As colonial seabirds represent an abundant and predictable resource for nest-inhabiting ectoparasites, there is little need for ticks to move once successfully established. The aggregation of ticks among hosts would be a natural consequence of limited dispersal combined with recent colonisation (Poulin, 1998). Ticks also tend to aggregate within sheltered areas in the off-host habitat (Sonenshine, 1993). For ticks parasitising kittiwakes, these refuges consist of cracks in the cliff face. If these different factors play an important role in determining infestation patterns, we expect that the aggregated and autocorrelated nature of tick infestation should be reflected in the local genetic structure of the tick population, that is, we should detect substructuring of ticks at the within-cliff scale and patterns of isolation by distance between host nests.

Observed patterns of tick infestation may also be related to spatial variation in the availability of susceptible hosts. Indeed, a heritable susceptibility to infestation by ticks has been previously shown in kittiwakes (Boulinier et al, 1997). If host susceptibility is largely responsible for patterns of spatial aggregation in this parasite, we do not necessarily expect ticks to be genetically structured within host patches as they could potentially disperse among all local, susceptible hosts.

For both of these possibilities, spatial genetic structure may differ depending on the age class of parasites within the population (Epperson and Alvarez-Buylla, 1997). Females of $I$. uriae lay a single batch of several hundred eggs in the off-host refuge. If dispersal is at least partially limited at the within-cliff scale, this should result in high local structure of larval ticks due to an aggregation of siblings. Depending on dispersal rates, this structure may then decline with each consecutive stage as dispersal probability increases and differential mortality occurs.

To attempt to distinguish among the different explanations for patterns of tick aggregation and to consider more generally the impact of host spatial distribution on parasite population structure, we analysed data for eight microsatellite markers from individual ticks collected in three host breeding cliffs.

\section{Methods}

\section{Sampling}

Ticks of all stages, except adult males, were sampled on kittiwake nestlings in three breeding cliffs, two (CG and CF) on the island of Horn $\varnothing y a$ in northern Norway $\left(70^{\circ} 22^{\prime} \mathrm{N}, 31^{\circ} 10^{\prime} \mathrm{E}\right)$ and one (LH) at Cape St Mary's, Newfoundland, Canada $\left(46^{\circ} 50^{\prime} \mathrm{N}, 54^{\circ} 12^{\prime} \mathrm{W}\right)$. For each cliff, a map of relative nest locations was constructed (Figure 1). The ability to sample nests depended on three factors. The first was the ability to access the nest site. For cliff LH, static climbing techniques were employed in 
424
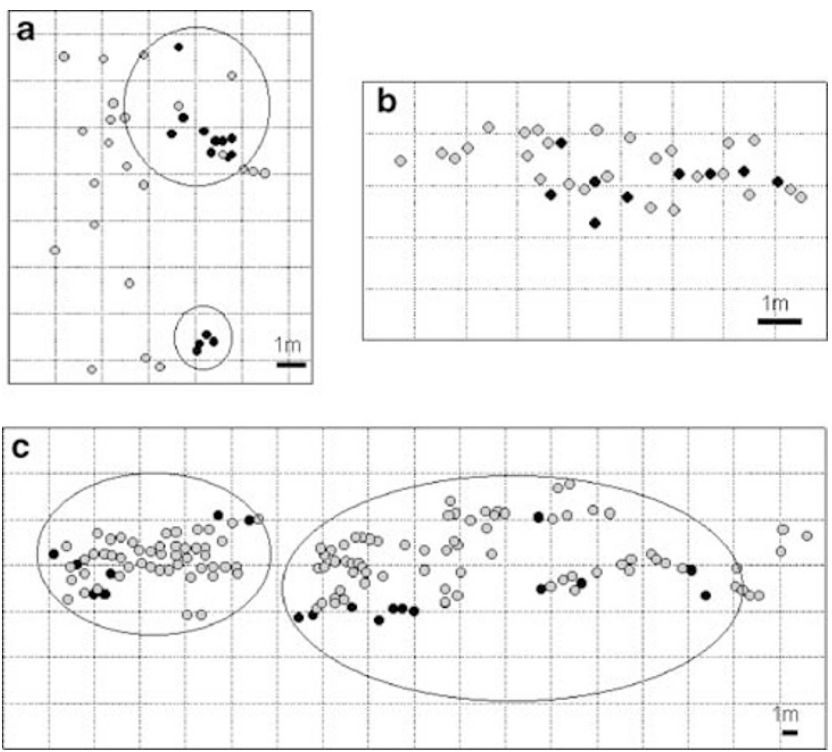

Figure 1 Relative nest locations in three kittiwake cliffs sampled for ticks: (a) cliff LH, Newfoundland, Canada, and cliffs (b) CF and (c) CG on the island of Hornøya, Norway. Circles indicate nest sites and black circles indicate those nests where ticks were sampled. On maps (a) and (c), nests enclosed within ellipses show the nest groups used in analyses. These groups were defined based on the clustering of nests and topographical features of the cliff. Note that the size of cliffs should not be directly compared as the distance between nests is relative to the individual cliff.

order to reach nests, while on Hornøya, all nests were accessed by free climbing. The second factor was the presence or absence of chicks in the nest. Adult birds can be quite efficient at grooming off ectoparasites, and ticks infesting these individuals may represent both resident and immigrant ticks. We therefore sampled ticks from chicks, which are confined to the nest site until fledging ( $\sim 35$ days). The third limiting factor was the cliff infestation level and the degree of aggregation of the parasite, both of which are highly variable depending on the colony (Danchin, 1992; Boulinier and Danchin, 1996; McCoy et al, 1999). The prevalence (\% of infested nests) and density of ticks (number of ticks per individual per nest) were similar in cliffs CF and $\mathrm{LH}(92 \%$ and $8.92 \pm 2.01$ in $\mathrm{CF} ; 91 \%$ and $8.40 \pm 2.14$ in $\mathrm{LH})$, but were lower in cliff CG $(83 \%$ and $3.07 \pm 0.66)$.

Sampled ticks were stored in $70-90 \%$ ethanol. DNA extractions and PCR amplifications for the eight microsatellite loci were carried out as described in McCoy and Tirard (2000).

\section{Data analysis}

Within population diversity and linkage disequilibrium: The number of alleles and gene diversity (Nei, 1987) were calculated for each cliff population using FSTAT v.2.9.1 (Goudet, 1995). Differences in the number of sampled alleles between cliffs were tested for significance by calculating a global estimate across all populations for each locus (based on Chakraborty's (1990) $\theta$ ) and determining the exact probability of sampling more or less alleles in a population given the number of individuals sampled (program provided by $\mathrm{L}$ Excoffier). Differences in gene diversity estimates were compared among cliffs using a Kruskal-Wallis test (SAS Institute, 1990, Cary, NC, USA). Linkage disequilibrium between loci for each cliff was examined using the exact probability test implemented in GENEPOP v.3.3 (Raymond and Rousset, 1995).

Hierarchical analyses: The distribution of genetic diversity within cliffs was analysed using Wright's Fstatistics as estimated according to Weir and Cockerham (1984). In a first analysis, ticks from each nest site were considered as subpopulations within a cliff. Only those nests with at least three ticks were considered for this analysis. Hardy-Weinberg equilibrium within nests was tested using $F_{\text {IS }}$ (estimated by $f$ ) and within a cliff using $F_{\mathrm{IT}}$ (estimated by $F$ ). $F_{\mathrm{ST}}$ (estimated by $\theta$ ) thus reflected differentiation between ticks of different nests. Estimates were calculated and tested for significance using the program FSTAT v.2.9.1. (Goudet, 1995). Significance values of $f$ and $F$ were calculated by permuting alleles among individuals either within a nest or within the cliff (5000 resamplings). The significance of $\theta$ was tested using an exact G-test by permuting genotypes between nests (5000 resamplings) (Goudet et al, 1996). This analysis was first performed for all ticks and then separately for each tick stage, when possible. Owing to the limited number of ticks available per nest, we consider this to be a conservative test of within-cliff population structure. If tests were highly sensitive to allele frequency estimations, permutation tests should reveal nonsignificant estimators of structure.

In a second analysis, we used the topographical characteristics of each cliff to define groups (ie, clustering of seabird nests or presence of cracks that might act as tick refuges). For cliff LH, two groups were evident from the spatial clustering of nests and the presence of a gap in the cliff face (Figure 1). For cliff $C G$, two groups were naturally formed by the structure of the cliff; the two areas with nests were separated by a smooth part of the cliff with no fissures or nest sites (Figure 1). Nest locations of cliff CF were relatively homogeneous throughout the cliff compared to the other two sites and no topographical division of the cliff was evident. Cliff CF was therefore excluded from this analysis. Hierarchical analyses were carried out as described above, except that each group within the cliff was treated as a subpopulation. Again, this analysis was performed for all ticks and, when possible, for each stage separately.

Spatial autocorrelation: The distribution of alleles within each cliff was studied by spatial autocorrelation analysis (eg, Sokal and Oden, 1978; Heywood, 1991) using the program SPAGeDi v1.0c (Hardy and Vekemans, 2002). Within each cliff, six distance classes were defined such that there were approximately equal numbers of pairwise comparisons in each class. The first distance class included individuals of the same nest (distance $=0$ ). Within each class, the coefficient of kinship $(\rho)$ was estimated using the method of Loiselle et al (1995). This index represents the correlation in allelic states between homologous genes and weights allele contributions by the product $p_{l a}\left(1-p_{l a}\right)$, where $p_{l a}$ is the ath allele frequency at locus $l$. It allows for the incorporation of multiple alleles and loci and is relatively unbiased in the presence of low-frequency 
alleles (Loiselle et al, 1995). For the zero distance class, this estimate represents an inbreeding coefficient at the scale of the cliff $\left(=F_{\mathrm{IT}}\right)$. Kinship statistics for SPAGeDi's intragroup class correspond to an estimate of $F_{\mathrm{ST}}$. To test the signifi-cance of these estimators, they were compared to the distribution of the statistics under the null hypothesis of no spatial structure generated using 10000 resamplings of the data, permuting alleles among individuals (for the inbreeding coefficient) and individuals among nest groups (for the intragroup class). For the kinship coefficients of the other distance classes (classes 1-5), spatial locations were permuted among nest groups.

The slope of the regression of pairwise kinship coefficients and pairwise logarithm of geographic distance was used to test for isolation by distance (Hardy and Vekemans, 1999). The significance of this relationship was determined by permuting spatial locations among the nest groups (in all cases at least eight nest locations were involved). To assure that tests of isolation by distance were not sensitive to the distribution of dispersal distances, we performed a second test using the individual-based method of Rousset (2000) as implemented in Genepop v3.3 (Raymond and Rousset, 1995). As above, this analysis was performed for all tick stages together, and then separately for each stage when possible.

\section{Results}

A total of 173 ticks were genotyped for the eight loci, including 96 adults, 38 nymphs and 39 larvae. The number of individuals genotyped of each tick stage differed among cliffs (Table 1) and was related to the ability to sample these stages from the birds (see

Table 1 Genetic diversity of tick populations within each kittiwake breeding cliff

\begin{tabular}{|c|c|c|c|c|c|c|}
\hline & \multicolumn{2}{|c|}{$\begin{array}{c}L H \\
\mathrm{n}=79(48,27,4) \\
\mathrm{n}_{l o c}=14\end{array}$} & \multicolumn{2}{|c|}{$\begin{array}{c}C F \\
\mathrm{n}=49(37,6,6) \\
\mathrm{n}_{l o c}=9\end{array}$} & \multicolumn{2}{|c|}{$\begin{array}{c}C G \\
\mathrm{n}=45(11,5,29) \\
\mathrm{n}_{l o c}=20\end{array}$} \\
\hline & $\mathrm{N}_{a}$ & $\mathrm{~h}$ & $\mathrm{~N}_{a}$ & $\mathrm{~h}$ & $\mathrm{~N}_{a}$ & $\mathrm{~h}$ \\
\hline T3 & 4 & 0.375 & 3 & 0.571 & 3 & 0.489 \\
\hline T5 & 7 & 0.720 & 8 & 0.686 & 8 & 0.759 \\
\hline $\mathrm{T} 22$ & 7 & 0.724 & 8 & 0.793 & 10 & 0.810 \\
\hline T35 & 7 & 0.649 & 8 & 0.804 & 8 & 0.884 \\
\hline T38 & 4 & 0.515 & 5 & 0.700 & 7 & 0.727 \\
\hline T39 & 14 & 0.846 & 16 & 0.850 & 18 & 0.828 \\
\hline T44 & 2 & 0.016 & 6 & 0.307 & 5 & 0.258 \\
\hline $\mathrm{T} 47$ & 2 & 0.174 & 3 & 0.344 & 4 & 0.309 \\
\hline \multirow[t]{2}{*}{ Average $( \pm S E)$} & 5.88 & 0.50 & 7.13 & 0.63 & 7.88 & 0.63 \\
\hline & $( \pm 1.38)$ & $( \pm 0.10)$ & $( \pm 1.47)$ & $( \pm 0.07)$ & $( \pm 1.66)$ & $( \pm 0.09)$ \\
\hline
\end{tabular}

The total number of individuals genotyped $(n)$ in each population are noted, with the number of adult, nymphal and larval ticks in parentheses. The number of different nest locations ( $n_{\text {loc }}$ sampled is also provided. $N_{\mathrm{a}}$ refers to the number of alleles sampled and $h$ to Nei's (1987) diversity index.

Table 2 Estimates of Wright's F-statistics (Weir and Cockerham, 1984) for tick populations of three kittiwake breeding cliffs

\begin{tabular}{|c|c|c|c|c|c|c|c|c|}
\hline Cliff & Stage & $\mathrm{n}$ & $\begin{array}{c}F \\
( \pm S E)\end{array}$ & $\mathrm{P}$ & $\begin{array}{c}\theta \\
( \pm S E)\end{array}$ & $\mathrm{P}$ & $\begin{array}{c}\mathrm{f} \\
( \pm S E)\end{array}$ & $\mathrm{P}$ \\
\hline \multirow[t]{2}{*}{ CG } & All & 7 & $\begin{array}{c}0.16 \\
(0.07)\end{array}$ & $<0.001$ & $\begin{array}{c}0.11 \\
(0.04)\end{array}$ & $<0.001$ & $\begin{array}{c}0.06 \\
(0.07)\end{array}$ & 0.116 \\
\hline & Larva & 5 & $\begin{array}{c}0.12 \\
(0.05)\end{array}$ & 0.009 & $\begin{array}{c}0.13 \\
(0.03)\end{array}$ & $<0.001$ & $\begin{array}{c}-0.02 \\
(0.05)\end{array}$ & 0.615 \\
\hline \multirow[t]{2}{*}{$\mathrm{CF}$} & All & 9 & $\begin{array}{c}0.16 \\
(0.05)\end{array}$ & $<0.001$ & $\begin{array}{c}0.006 \\
(0.02)\end{array}$ & 0.027 & $\begin{array}{c}0.15 \\
(0.05)\end{array}$ & $<0.001$ \\
\hline & Adult & 7 & $\begin{array}{c}0.13 \\
(0.07)\end{array}$ & $<0.001$ & $\begin{array}{r}0.010 \\
(0.02)\end{array}$ & 0.066 & $\begin{array}{c}0.12 \\
(0.06)\end{array}$ & 0.004 \\
\hline \multirow[t]{3}{*}{$\mathrm{LH}$} & All & 14 & $\begin{array}{c}0.14 \\
(0.06)\end{array}$ & $<0.001$ & $\begin{array}{c}0.034 \\
(0.02)\end{array}$ & 0.006 & $\begin{array}{c}0.11 \\
(0.05)\end{array}$ & 0.002 \\
\hline & Nymph & 5 & $\begin{array}{c}0.22 \\
(0.08)\end{array}$ & $<0.001$ & $\begin{array}{c}0.013 \\
(0.05)\end{array}$ & 0.317 & $\begin{array}{c}0.21 \\
(0.08)\end{array}$ & 0.004 \\
\hline & Adult & 8 & $\begin{array}{c}0.04 \\
(0.06)\end{array}$ & 0.188 & $\begin{array}{c}-0.004 \\
(0.02)\end{array}$ & 0.797 & $\begin{array}{c}0.04 \\
(0.06)\end{array}$ & 0.181 \\
\hline
\end{tabular}

All ticks from the same nest were considered as a subpopulation ( $n=$ the number of nests used in each analysis). The $P$-values of estimators were calculated by permuting alleles/genotypes within/between nests with 5000 resamplings (Goudet, 1995). Standard errors were calculated by jack-knifing across loci (Goudet, 1995). 
Methods). The numbers of alleles detected were similar for the two cliffs on Hornøya (CF, CG), but were slightly reduced for cliff LH (Table 1). After correction for multiple tests (Rice, 1989), there was no significant difference among the three cliffs. Estimated gene diversity did not vary significantly among cliffs $\left(\chi^{2}=1.46, P=0.48\right)$ (Table 1$)$ and only a single pairwise test of linkage disequilibrium was significant after correction for the number of tests performed within each cliff (cliff LH:T3 and T35, $P=0.0012$ ).

The results of the hierarchical analysis with nests defined as subpopulations are summarised in Table 2. For all the three cliffs, values of $F$ were significant. However, the causes of the subdivision seemed to be different. In cliff CG, the overall $F$ value was due to differentiation between ticks in different nests $(\theta=0.11)$. For cliffs $\mathrm{LH}$ and $\mathrm{CF}$, most structure seemed to be due to an excess of homozygotes within nests $(f=0.11$ and 0.15 , respectively) (Table 2$)$. We could not examine differences in substructure for all tick stages within the same cliff owing to low sample sizes. However, for cliff LH, where enough adults and nymphs were genotyped, estimates of substructure were higher for nymphs than for adults (Table 2).

When the hierarchical analysis was repeated using nest groups, as defined by the spatial arrangement of nests and the topographical features of the cliff (Figure 1), significant differentiation was found between groups $(\theta$, Table 3$)$. For cliff CG, the amount of substructuring explained by the within-group structure increased $(f)$ and the between-group structure was lower $(\theta)$, compared to the hierarchical analysis based on nests. This suggests that the nest level is the more relevant unit of structure for this cliff. In cliff $\mathrm{LH}$, the pattern was more complicated and depended on the stage considered. For all ticks, the change in the pattern of substructuring was similar to that of cliff CG (Table 3). However, if we examine the results for each stage separately, we see that adult ticks showed significant between-group differentiation $(\theta$, Table 3$)$, whereas there was no between-nest differentiation in the first analysis $(\theta$, Table 2). Owing to the reduced number of nymphal ticks in group 1 (Table 3 ), the nonsignificance of the between-group estimator $(\theta)$ for nymphs is likely linked to the sample size, and thus should be taken with caution. Overall, however, it seems that topography and the spatial arrangement of nests may be more important in determining population structure in cliff LH than in cliff CG.

There was no evidence for spatial autocorrelation of kinship coefficients in the three cliffs examined. The results at the zero distance class, corresponding to the inbreeding coefficient $\left(F_{\mathrm{IT}}\right)$ and the intragroup class $\left(F_{\mathrm{ST}}\right)$, mirrored those found in the first hierarchical analysis (Table 2, Figure 2). Similarly, structuring at this distance class decreased with consecutive tick life stages (Figure 2). For all the cliffs, the kinship coefficient did not differ significantly from zero at any other distance class (all $P$-values $>0.05$ ) and there was no evidence for isolation by distance within cliffs, whether tick stages were considered separately or together (all $P$-values $>0.05)$. Tests for isolation-by-distance based on Rousset's (2000) method were also nonsignificant for the three cliffs (all $P$-values $>0.05$ ).
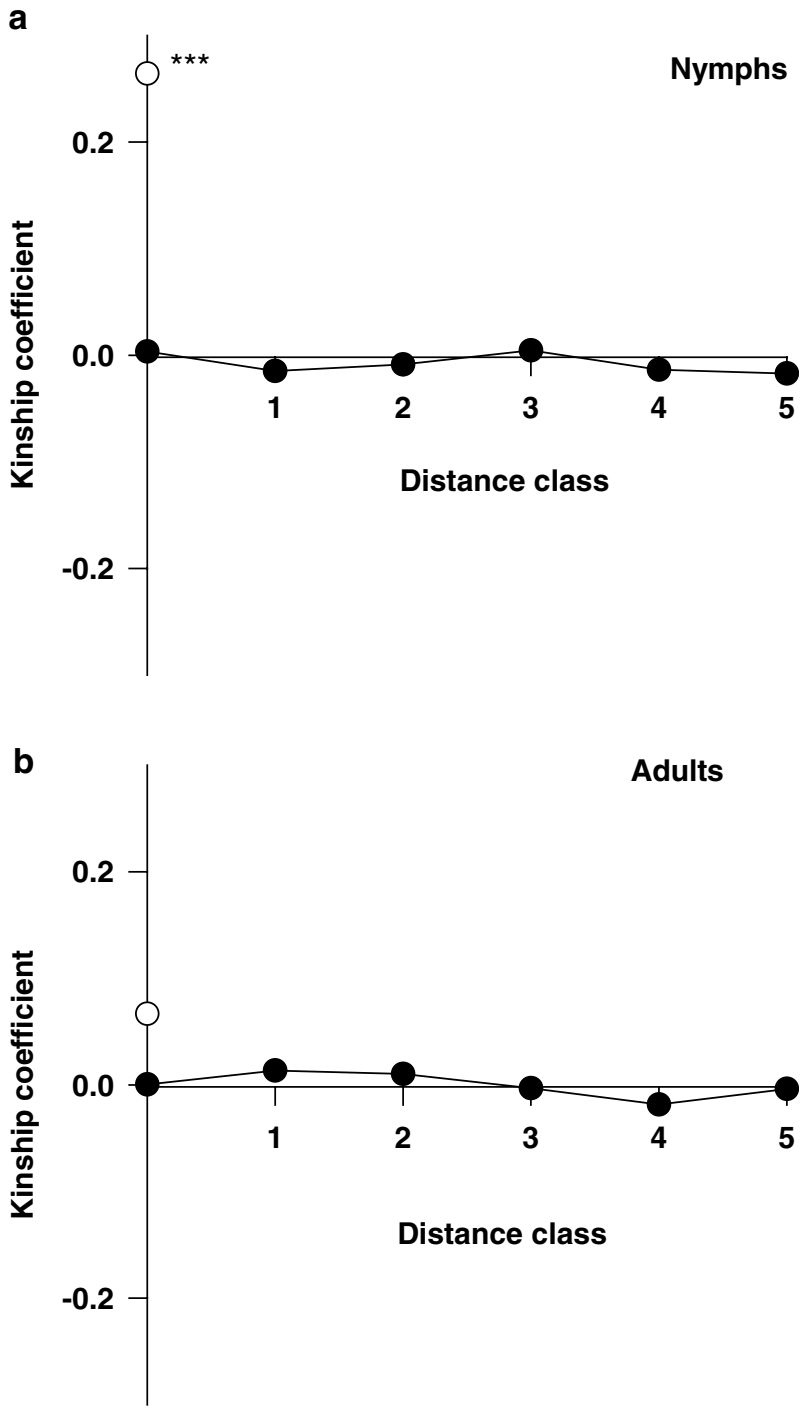

Figure 2 Kinship coefficients $(\rho)$ as a function of the relative distance between (a) nymphal and (b) adult tick groups of cliff LH. Kinship coefficients were calculated following Loiselle et al (1995) and represent the mulilocus estimate for eight microsatellite loci. There were no significant deviations of kinship coefficients from values expected under random distributions for any distance class. At the zero distance class, open symbols represent inbreeding coefficients $\left({ }^{* * *} P<0.001\right)$ and closed symbols represent the intragroup kinship coefficient (corresponding to an estimate of between-nest differentiation, or $F_{\mathrm{ST}}$ ).

\section{Discussion}

Here, we examined the spatial genetic structure of a seabird ectoparasite within host subpopulations, corresponding to different breeding patches. At this scale, ticks are naturally aggregated and their presence is spatially autocorrelated (Boulinier et al, 1996; McCoy et al, 1999). We found that the genetic structure of these ectoparasites partially mirrors this spatial pattern of infestation. Tick populations were genetically substructured in all the three cliffs considered. However, the nature of the substructuring differed among cliffs. In cliffs $\mathrm{CF}$ and $\mathrm{LH}$, where tick population densities were high, heterozygote deficits within nests $\left(F_{\text {IS }}\right)$ may be 
Table 3 Estimates of Wright's F-statistics (Weir and Cockerham, 1984) for tick populations of kittiwake breeding cliffs CG, Horn $\varnothing y a$ and LH, Newfoundland

\begin{tabular}{|c|c|c|c|c|c|c|c|}
\hline Cliff & Stage & $\begin{array}{c}F \\
( \pm S E)\end{array}$ & $\mathrm{P}$ & $\begin{array}{c}\theta \\
( \pm S E)\end{array}$ & $\mathrm{P}$ & $\begin{array}{c}\mathrm{f} \\
( \pm S E)\end{array}$ & $\mathrm{P}$ \\
\hline \multirow[t]{2}{*}{ CG } & $\begin{array}{l}\text { All } \\
(16 / 29)\end{array}$ & $\begin{array}{c}0.17 \\
(0.05)\end{array}$ & & $\begin{array}{c}0.034 \\
(0.01)\end{array}$ & 0.002 & $\begin{array}{c}0.14 \\
(0.05)\end{array}$ & $<0.001$ \\
\hline & $\begin{array}{l}\text { Larva } \\
(12 / 17)\end{array}$ & $\begin{array}{c}0.14 \\
(0.05)\end{array}$ & $<0.001$ & $\begin{array}{c}0.044 \\
(0.01)\end{array}$ & $<0.001$ & $\begin{array}{c}0.103 \\
(0.05)\end{array}$ & 0.009 \\
\hline \multirow[t]{3}{*}{ LH } & $\begin{array}{l}\text { All } \\
(32 / 47)\end{array}$ & $\begin{array}{c}0.15 \\
(0.06)\end{array}$ & $<0.001$ & $\begin{array}{r}0.015 \\
(0.01)\end{array}$ & $<0.001$ & $\begin{array}{c}0.14 \\
(0.06)\end{array}$ & $<0.001$ \\
\hline & $\begin{array}{l}\text { Nymph } \\
(8 / 19)\end{array}$ & $\begin{array}{c}0.23 \\
(0.06)\end{array}$ & $<0.001$ & $\begin{array}{c}0.013 \\
(0.02)\end{array}$ & 0.139 & $\begin{array}{c}0.22 \\
(0.05)\end{array}$ & $<0.001$ \\
\hline & $\begin{array}{l}\text { Adult } \\
(20 / 28)\end{array}$ & $\begin{array}{c}0.07 \\
(0.06)\end{array}$ & 0.031 & $\begin{array}{c}0.016 \\
(0.01)\end{array}$ & 0.008 & $\begin{array}{c}0.06 \\
(0.06)\end{array}$ & 0.066 \\
\hline
\end{tabular}

Ticks were divided into two groups (subpopulations) in each cliff site based on topographical characteristics. The number of ticks included in each group are indicated in parentheses below the tick stage. The $P$-values of estimators were calculated by permuting alleles/genotypes within/between groups with 5000 resamplings (Goudet, 1995). Standard errors were calculated by jack-knifing across loci (Goudet, 1995).

more related to a mixture of different family groups (Wahlund effect) than to local inbreeding, as there was low differentiation at the between-nest scale. However, in cliff CG, where the density of ticks was lower, ticks showed high between-nest differentiation. These results suggest that tick dispersal may change with population density such that as parasite density increases, we see reduced genetic structure within each cliff. However, it should be noted that a large number of larval ticks were genotyped in cliff CG and thus, the greater structure found here might also be associated with stage-dependent patterns of structure (see below). Globally, the presence of genetic structure at the within-cliff scale suggests that observed patterns of tick aggregation are more likely the product of tick dynamics and dispersal rather than the spatial arrangement of susceptible hosts. Although we expected no structure if aggregation was solely due to spatial variation in host susceptibility, the ability of hosts to resist ectoparasite infestation may still be important at some local level; many factors likely act in concert to shape local parasite population structure.

In order to colonise a site initially, ticks must be dispersed by their bird hosts. Thereafter, the local buildup of ticks may be either through local population growth with internest dispersal, or through multiple, independent colonisation events to each nest site. As seabirds return each year to the same nest site to breed, the motivation for ticks to disperse, even between nests, may be low. Observations on the local dynamics of infestation have suggested that the spatial autocorrelation of tick infestation may be related to local dispersal from the initial colonisation site (Boulinier, 1995). In particular, a single breeding cliff at Cape Sizun, France was monitored over a 12-year period from initial tick infestation. Once $20 \%$ of the nests were infested, a positive autocorrelation in the presence of ticks was found within a few metres of the infested nest. With increasing infestation, the area where the positive autocorrelation occurred increased to include a slightly larger distance class, suggesting a local spread of ticks between nearby nests. Here, we found that ticks were significantly structured among nests (distance class $=0$ ), but no other distance class showed significant, positive estimates of kinship coefficients. However, for all the three cliffs considered, the prevalence of infestation was much greater than $20 \%$ (83-92\%). Thus, it may be that local dispersal processes are important during the initial phases of local population expansion, but that this structure breaks down once populations become large. Our results partially support this hypothesis. Sampled ticks were more strongly structured in cliff CG where the density of infestation was lower. However, we did not find a significant spatial autocorrelation in allele frequencies in this less infested cliff. Furthermore, estimates of gene diversity and the numbers of alleles did not support the idea that the infestation of this cliff was necessarily more recent than the other two. To test the relative roles of local dispersal and multiple colonisation events in the local dynamics of tick populations, ticks sampled from more lightly infested cliffs $(<80 \%$ infestation) will be required.

The topographic structure of the cliff also seemed to shape the genetic structure of tick populations. When ticks were grouped according to the spatial distribution of nests, significant differentiation was found. This was particularly true for cliff LH where adult ticks showed no structure at the between-nest level (Table 2), but significant differentiation between nest groups (Table 3 ). Ticks spend long periods of time off the host and must find appropriate shelters in order for populations to persist locally. The availability of shelters in close proximity to host nests may be an essential factor shaping local population dynamics and may drive the spatial subdivision of ticks. The general importance of habitat in the evolution of ticks has been debated (Klompen et al, 1996). Our results support the idea that habitat may play a predominant role in the coevolutionary outcomes of this system (eg, evolution of resistance/virulence or local adaptation).

Epperson and Alvarez-Buylla (1997) found that tropical tree seedlings showed strong spatial autocorrelation at local scales, but that this structure disappeared in older age groups. They suggested that this was due to low seed dispersal that resulted in the clustering of progeny. With increased competition in older age classes and the natural thinning of the population, this structure disappeared. Although our ability to test this hypothesis for I. uriae was limited due to sampling constraints, we 
expected the same type of phenomenon to occur. Females lay a single large batch of eggs that will cluster her progeny locally. As dispersal opportunities should increase each time the tick takes a blood meal on the host and earlier life stages are more susceptible to mortality factors (Sonenshine, 1993), we expected the genetic structure to be reduced in each consecutive life stage. Indeed, we found elements suggesting that this does occur in populations of I. uriae. However, as there was no evidence of isolation by distance within cliffs, it may be that tick dispersal between nests depends almost entirely on host movements (which will not necessarily be local; McCoy et al, 2003). Age-dependent spatial structure may also occur in populations of other hard tick species (eg, I. ricinus), but for non-nidicolous (open habitat) species we would expect the genetic structure set-up by clustered progeny to decrease more rapidly than in nidicolous (enclosed habitat) species owing to the more continuous distribution of host individuals.

Here, we have shown that ticks may be spatially subdivided within local subpopulations of their hosts and that this structure may be linked to both abiotic factors (ie, cliff topography) and life history traits of the parasite itself (eg, clustered progeny and low dispersal). This spatial genetic structure has several implications for local population functioning. It may modify the probability of population persistence, the timing and nature of infestation dynamics and the constraints acting on local parasite groups. Furthermore, such spatial structure may greatly affect the scale and outcome of coevolutionary processes. Few studies have looked at parasite population structure, and particularly at small spatial scales. Given the potential implications of spatial genetic structure, our results stress the importance of considering local parasite dynamics in order to better understand the ecology and evolution of host-parasite interactions.

\section{Acknowledgements}

We are grateful to T Boulinier, JW Chardine, R Barrett and $\mathrm{T}$ Tveraa for assistance with fieldwork. O Hardy and L Excoffier kindly provided programs used for data analysis. We also thank T Boulinier, C Doums and two anonymous referees for comments on a previous draft of this manuscript. The permit to work in the Cape St Mary's Reserve was provided by the Parks and Natural Areas Division, Government of Newfoundland and Labrador. In Norway, work on Hornøya was carried out with the permission of the Finnmark County Government. Funding for this research was provided by the French Polar Institute (IPEV, program 'Parasitoarctique') and the CNRS (Program 'Environnement, Vie et Societé'), France. KDM benefited from post-graduate scholarships provided by NSERC, Canada, and the Ministry of Foreign Affairs, France.

\section{References}

Antonovics J, Thrall PH, Jarosz AM (1997). Genetics and the spatial ecology of species interactions: the Silene-Ustilago system. In: Tilman D, Kareiva P (eds) Spatial Ecology. The Role of Space in Population Dynamics and Interspecific Interactions, Princeton University Press: Princeton. pp 158-180.
Blouin MS, Liu J, Berry RE (1999). Life cycle variation and the genetic structure of nematode populations. Heredity $\mathbf{8 3}$ : 253-259.

Boulinier T (1995). Sélection de l'habitat de reproduction, facteurs environnementaux et fonctionnement des populations d'oiseaux coloniaux: cas des interactions hôte-parasite entre la Mouette tridactyle Rissa tridactyla et la tique Ixodes uriae. PhD Thesis, Université Paris VI, Paris.

Boulinier T, Danchin E (1996). Population trends in kittiwake Rissa tridactyla colonies in relation to tick infestation. Ibis 138: 326-334.

Boulinier T, Ives A, Danchin E (1996). Measuring parasite aggregation at different host population levels. Parasitology 112: 581-587.

Boulinier T, McCoy KD, Sorci G (2001). Dispersal and parasitism. In: Clobert J, Danchin E, Dhondt A, Nichols JD (eds) Dispersal, Oxford University Press: Oxford. pp 169-179.

Boulinier T, Sorci G, Monnat J-Y, Danchin E (1997). Parentoffspring regression suggests heritable susceptibility to ectoparasites in a natural population of kittiwake Rissa tridactyla. J Evol Biol 10: 77-85.

Chakraborty R (1990). Mitochrondrial DNA polymorphism reveals hidden heterogeneity within some Asian populations. Am J Hum Genet 47: 87-94.

Dame JB, Blouin MS, Courtney CH (1993). Genetic structure of populations of Ostertagia ostertagi. Vet Parasitol 46: 55-62.

Danchin E (1992). The incidence of the tick parasite Ixodes uriae in kittiwake Rissa tridactyla colonies in relation to the age of the colony and the mechanism of infecting new colonies. Ibis 134: 134-141.

Danchin E, Boulinier T, Massot M (1998). Conspecific reproduction success and breeding habitat selection: implications for the study of coloniality. Ecology 79: 2415-2428.

Epperson BK, Alvarez-Buylla ER (1997). Limited seed dispersal and genetic structure in life stages of Cecropia obtusifolia. Evolution 51: 275-282.

Eveleigh ES, Threlfall W (1974). The biology of Ixodes (Ceratixodes) uriae White, 1852 in Newfoundland. Acarologia 16: 621-635.

Falco RC, Fish D (1991). Horizontal movement of adult Ixodes dammini (Acari: Ixodidae) attracted to $\mathrm{CO}_{2}$-baited traps. J Med Entomol 28: 726-729.

Goudet J (1995). FSTAT (vers. 1.2): a computer program to calculate F-statistics. J Hered 86: 485-486.

Goudet J, Raymond M, de Meeûs T, Rousset F (1996). Testing differentiation in diploid populations. Genetics 144: 1993-1940.

Hardy OJ, Vekemans X (1999). Isolation by distance in a continuous population: reconciliation between spatial autocorrelation analysis and population genetic models. Heredity 83: 145-154.

Hardy OJ, Vekemans X (2002). SPAGeDi: a versatile computer program to analyse spatial genetic structure at the individual or population levels. Mol Ecol 2: 618-620.

Heywood JS (1991). Spatial analysis of genetic variation in plant populations. Ann Rev Ecol Syst 22: 335-355.

Jobet E, Durand P, Langand J, Müller-Graf CDM, Hugot J-P, Bougnoux M-E et al (2000). Comparative genetic diversity of parasites and their hosts: population genetic structure of an urban cockroach and its haplo-diploid parasite (oxyuroid nematode). Mol Ecol 9: 481-486.

Klompen JSH, Black WC IV, Keirans JE, Oliver Jr JH (1996). Evolution of ticks. Ann Rev Entomol 41: 141-161.

Loiselle BA, Sork VL, Nason J, Graham C (1995). Spatial genetic structure of a tropical understory shrub, Psychotria officinalis (Rubiaceae). Am J Bot 82: 1420-1425.

McCoy KD, Boulinier T, Chardine JW, Danchin E, Michalakis Y (1999). Dispersal and distribution of the tick Ixodes uriae within and among seabird host populations: the need for a population genetic approach. J Parasitol 85: 196-202. 
McCoy KD, Boulinier T, Tirard C, Michalakis Y (2001). Host specificity of a generalist parasite: genetic evidence of sympatric host races in the seabird tick Ixodes uriae. J Evol Biol 14: 395-405.

McCoy KD, Boulinier T, Tirard C, Michalakis Y (2003). Hostdependent genetic structure of parasite populations: differential dispersal of seabird tick host races. Evolution 57: 288-296.

McCoy KD, Tirard C (2000). Isolation and characterisation of microsatellites in the seabird ectoparasite Ixodes uriae. Mol Ecol 9: 2213-2214.

Morbey YE (1996). The abundance and effects of ticks (Ixodes uriae) on nestling Cassin's Auklets (Ptychoramphus aleuticus) at Triangle Island, British Columbia. Can J Zool 74: 1585-1589.

Mulvey M, Aho JM, Lydeard C, Leberg PL, Smith MH (1991). Comparative population genetic structure of a parasite (Fascioloides magna) and its definitive host. Evolution 45: $1628-1640$

Nei M (1987). Molecular Evolutionary Genetics. Columbia University Press: New York.

Olsen B, Jaenson TGT, Noppa L, Bunikis J, Bergstrom S (1993). A Lyme borreliosis cycle in seabirds and Ixodes uriae ticks. Nature 362: 340-342.
Poulin R (1998). Evolutionary Ecology of Parasites: From Individuals to Communities. Chapman \& Hall: London.

Raymond M, Rousset F (1995). GENEPOP (version 1.2): population genetics software for exact tests and ecumenicism. J Hered 86: 248-249.

Rice WR (1989). Analyzing tables of statistical tests. Evolution 43: 223-225.

Rousset F (2000) Genetic differentiation between individuals. J Evol Biol 13: 58-62.

Shaw DJ, Dobson AP (1995). Patterns of macroparasite abundance and aggregation in wildlife populations: a quantitative review. Parasitology 111: S111-S133.

Sokal RR, Oden NL (1978). Spatial autocorrelation in biology. I. Methodology. Biol J Linn Soc 10: 199-228.

Sonenshine DE (1993). Biology of Ticks. Oxford University Press: Oxford

Wassom DL, Dick TA, Arnason N, Strickland D, Grundmann AW (1986) Host genetics: a key factor in regulating the distribution of parasites in natural host populations. J Parasitol 72: 334-337.

Weir BS, Cockerham CC (1984). Estimating F-statistics for the analysis of population structure. Evolution 38: 1358-1370.

Wikel SK (1996). Host immunity to ticks. Ann Rev Entomol 41: 1-22. Wright S (1943). Isolation by distance. Genetics 28: 114-138. 